HISTORY OF MEDICINE

\title{
History of the development of geriatric medicine in the UK
}

\author{
A Barton, G Mulley
}

Postgrad Med J 2003;79:229-234

In this review the development of the specialty of geriatric medicine in the UK is traced from its humble beginnings. Elderly medicine is now thriving and represents the largest group of physician members of the Royal Colleges of Physicians. Geriatric medicine is essentially about optimising the care and wellbeing of older people. A key component of this is teamwork. A successful service for old people depends on the skills of many people, including nurses, therapists, social workers, and others. The contributions made by nurses and other professionals have been immense, but space does not permit a historical review of their important role.

See end of article for authors' affiliations

Correspondence to: Dr Alan Barton Department of Elderly Medicine, Great George Street, Leeds General Infirmary, Leeds LSI 3EX,

UK; abarton@ doctors.org.uk

Submitted

15 October 2002

Accepted

19 December 2002 n this review we shall concern ourselves with medicine and old age and focus on:

A. A historical perspective and the naming of the specialty.

B. Pioneers and heroes of the specialty, the birth of the British Geriatrics Society, the development of old age psychiatry and orthogeriatrics, and the expansion of geriatric medicine.

C. The question of integration of the specialty with general medicine.

D. Contemporary themes, including community geriatrics and the National Service Framework (NSF) for older people.

In medieval times, sick people were cared for in monasteries. Some religious orders built hospital wings where elderly and infirm patients received better food and received special care. Later, convents adopted a nursing role.

Poor Laws were passed in Parliament in 1597 and 1601 to keep the "poor" off the street, and avoid vagrancy and possible lawlessness. The Poor Law system became a regime which provided not only for those without money, but also provided accommodation to those who were ill, chronically sick, single parent families, and orphans. Workhouses (later renamed poorhouses) started in the 1630 s and by the end of the 1700s they had become asylums for the old, infirm, and insane. ${ }^{1}$ The conditions within were appalling and very harsh. At the time, poverty was believed to be associated with a decline in moral standards.

Thus individuals in poorhouses were prejudged and treated unfairly. Many more poorhouses were

\section{A. HISTORICAL BACKCLOTH}

built in Victorian times under the 1834 New Poor Law, to curtail public spending on poverty. ${ }^{2}$ Until 1834 individual parishes were responsible for their own poor. Parishes were united after 1834 and larger workhouses were known as unions; there were about 700 such institutions. The editor of the Lancet campaigned for improvements within poorhouses. (A previous editor had famously described the workhouse wards as "ante chambers of the grave ${ }^{\prime 2}{ }^{2}$ ) Joseph Rogers, a reformer of workhouses throughout his career as a doctor, gave advice on the conditions in Victorian workhouses. " "Workhouse medicine" failed its occupants, there was no casualty provision, no trained nursing staff, no drugs, and no surgical facilities. ${ }^{3}$ Conditions gradually improved for the inmates and laws were passed to safeguard their wellbeing.

The Poor Law ended with the Local Government Act of 1929. However, a two tier system of hospital care evolved. Power was transferred to local authorities who ran the infirmaries which developed from workhouses. Other hospitals were voluntary establishments, which enjoyed higher status and preferred not to admit older people. Elderly patients were considered as being of less interest for teaching and it was feared that they would block beds. These voluntary hospitals became the first teaching hospitals. The care of older people took place in former poor law hospitals, where staffing levels were poor and facilities inferior.

\section{Early publications}

One of the first publications on the subject of geriatric medicine was by George Day, whose Diseases of Advanced Life was published in 1849. ${ }^{45}$ Day documented some of the modern day "geriatric giants", 6 including incontinence and dementia. $\mathrm{He}$ also described vascular dementia, which “...follows slight attacks of apoplexy and paralysis; its progress is then very rapid". ${ }^{4}$

In 1881 Charcot was the first physician to advocate a specialty of geriatric medicine, based on his observations of a poorhouse-like institution in Paris. ${ }^{7}$ French physicians had previously used the phrase "Gerocomie" — a term used to describe the need for a separate facility for elderly people, where they could be adequately cared for and treated. ${ }^{8}$ They recognised that segregation of elderly people could help in improving their health and wellbeing.

Abbreviations: NSF, National Service Framework; UCH, University College Hospital 
Box 1: Warren's classification of the chronic aged sick ${ }^{1}$

- Chronic up-patients (that is, out of bed).

- Chronic continent bedridden patients.

- Chronic incontinent patients.

- Senile, quietly confused, but not noisy or annoying others.

- Senile dements-requiring segregation from other patients.

The word "geriatrics" comes from two Greek words; "iatros", a healer and "geros", an old man. Nascher, a Viennese immigrant to the US, first used the word geriatrics in $1909 .{ }^{9}$ His seminal paper not only was the first to name the specialty, but also considered the need for a separate specialty to deal with the problems of "senility". He used the analogy of medicine of childhood, which had been "assigned to a special branch of medicine" and suggested that geriatrics should be considered in a similar fashion. Nascher also focused on drug prescribing and warned of the harmful effects that medications (such as antidepressants) could have on the ageing heart. He also described the symptoms and mode of death in older people with pneumonia.

Though our specialty was first conceived and named in the US, it was in the UK that geriatric medicine was born over 30 years later.

\section{B. PIONEERS OF GERIATRIC MEDICINE IN THE UK Marjory Warren (1897-1960)}

The "mother of geriatrics", Warren was the most influential pioneering geriatrician. Few physicians were interested in looking after older people at the beginning of the 20th century. This situation changed after the appointment of Marjory Warren as assistant medical officer at the West Middlesex Hospital in $1926 .{ }^{10}$ In 1935, when the nearby Poor Law Infirmary was integrated into her own place of work, she was given the responsibility of caring for 714 chronically ill patients, many of them elderly.

She created the first geriatric unit in the UK. She systematically examined every new patient. Having separated the sick from the healthy, the old from the young, she instituted medical treatment and rehabilitation. Discharges were planned-an innovation at that time. As a result of her work, she reduced her number of chronic beds to 240 with a turnover three times the previous rate, and gave the unwanted beds to chest physicians for treating tuberculosis patients.

Simple measures were used to improve the hospital environment for patients and staff. The wards were repainted. New brightly coloured bed linen and curtains were installed. Lockers for individual patients were acquired, and for the first time patients were encouraged to get out of bed and walk. She attracted the attention of a health minister, who visited her department after her discharge rate reached $25 \%$.

Marjory Warren published 27 scientific papers on her approaches to rehabilitation in the 1940s and 1950s. These included her ideas on rehabilitation of disabled elderly people, especially stroke patients and amputees. In her two most important publications, she described her approach to the management and classification of chronically sick older people (box 1). ${ }^{11}{ }^{12}$ She strongly believed that elderly people with these conditions should be segregated from chronically sick patients of other ages, and treated in a separate geriatric assessment unit within the general hospital. This model of care would offer sick older people the best chance of diagnosis and treatment. In addition, their chances of discharge would be optimised. Warren echoed Charcot's call for a specialty of geriatrics. ${ }^{12}$ This would "stimulate better work and initiate research". She also requested a change in the attitude of all medical and nursing staff towards elderly patients.
As well as being a pioneer of rehabilitation, Marjory Warren was a gifted teacher. She educated junior medical staff and consultant colleagues and she took a keen interest in the education of nursing staff. Many of her ideas remain central to the practice of modern geriatric medicine.

\section{Joseph Sheldon (1893-1972)}

Sheldon was the father of community geriatric medicine. ${ }^{13}{ }^{14}$ He was a consultant at the Royal Hospital in Wolverhampton, where his interest in elderly people was prompted by an outbreak of food poisoning.

Sheldon observed many of the problems facing elderly people at home. He realised the importance of good self care, continence, hearing, and footwear. Of particular importance was his recognition of mobility problems: he documented that $11 \%$ of elderly people were housebound. Sheldon recommended home physiotherapy. This would eventually be recognised as standard treatment. He advocated falls prevention strategies, such as adequate lighting at home and the benefits of stair rails.

\section{Norman Exton-Smith (1920-90) and Lord Amulree (1900-83)}

An exceptional pioneering clinical scientist and researcher, Exton-Smith worked at University College Hospital (UCH) London, under the supervision of Lord Amulree. ${ }^{15} \mathrm{UCH}$ was for a long time the only London teaching hospital involved with the development of geriatrics. Amulree had previously worked at UCH, but in 1936 had become a civil servant at the Ministry for Health. His influence in the House of Lords proved useful in improving conditions for chronic sick patients for whom he cared deeply. With the inception of the National Health Service he wanted their care transferred from local authority control. This occurred in 1948. Following his consultant appointment, and inspired by the work of Marjory Warren, he set about improving the plight of elderly disabled patients, and also changing the drab wards of St Pancras Hospital (a part of UCH). His work with Exton-Smith was a huge success. Beds were made available as a result of hospital discharges. Elderly services expanded and UCH attracted some of the brightest and keenest junior doctors.

Both Amulree and Exton-Smith were proponents of continuing (that is, long term) care of older people and of home assessment visits (not requested by a general practitioner, undertaken by the geriatrician before hospital admission, and without remuneration) ${ }^{16-20}$ Amulree was present at the inaugural meeting of the British Geriatrics Society and was the first president, a post he held with merit for 25 years.

Exton-Smith also worked with Doreen Norton, who later became the first professor of gerontological nursing. ExtonSmith developed geriatric research and published extensively. He became the first professor of the specialty in London at UCH in 1973. A particular interest was pressure sores (he pioneered pressure mattresses and was involved in the design of the modern Ripple Mattress). ${ }^{21}$ Other research interests included temperature regulation, the autonomic nervous system, nutrition, and osteomalacia. ${ }^{22-25} \mathrm{His}$ interest in cognitive impairment resulted in the establishment of one of the first memory clinics. ${ }^{26}$

\section{George Adams (1916-)}

Another outstanding academic pioneer, he was the first geriatrician to teach geriatric medicine to undergraduates. ${ }^{27}$ He worked as houseman for Professor Thomson in Belfast's Royal Victoria Hospital and was inspired by his chief's compassion for patients on the chronic sick wards in the Poor Law infirmaries. He attended the first meeting of the Medical Society for the Care of the Elderly, later renamed the British Geriatrics Society. He met Marjory Warren and attended one of her ward rounds. After returning to Belfast, he wrote, "she 
Box 2: People present at the inaugural meeting of the Medical Society for the Care of the Elderly (later the British Geriatrics Society)

- Lord Amulree: member of the Ministry for Health. First president of the British Geriatrics Society, a position held for 25 years. He developed the geriatric unit at St Pancras Hospital in London (see text).

- Eric Brooke: physician superintendent at St Helier's Hospital, Carshalton, and later consultant geriatrician, Southampton. Originator of domiciliary assessment and pioneer of outpatient rehabilitation.

- Alfred Mitchell: physician superintendent of St John's Hospital, London.

- Lawrence Sturdee: senior medical officer at the Ministry for Health who chaired the first meeting. Major interest in public assistance institutions.

- Thomas Wilson: deputy superintendent of St John's Hospital. First treasurer of the British Geriatrics Society and became the first consultant geriatrician (in Cornwall) appointed to the NHS.

- George Adams (see text).

- Lionel Cosin (see text).

- Trevor Howell (see text).

- Marjory Warren (see text).

gave me a practical illustration of what we might one day hope to achieve with the human wreckage in the overcrowded wards of the City Hospital".

Adams later opened the first purpose-built elderly rehabilitation unit in the UK, Wakehurst House at Belfast City Hospital. He published widely, his particular research and clinical interests being cerebrovascular disease and disability. He was appointed to the chair of geriatrics in Belfast in 1971, only the second geriatrician at that time to occupy such a position, and served as president of the British Geriatrics Society.

\section{Birth of the British Geriatrics Society}

Trevor Howell was originally a general practitioner whose interest in elderly medicine was stimulated after he became responsible for the Chelsea pensioners. He was appointed consultant physician at Battersea and subsequently opened one of the first geriatric units there. ${ }^{28-30}$ In 1947 he called a meeting to bring together physicians and an orthopaedic surgeon (Lionel Cosin), who all had a special interest in older people. They had skills in rehabilitation, incontinence management, and domiciliary assessment (box 2).

The meeting was the first of the Medical Society for the Care of the Elderly. Nascher's term "geriatrics" was revived in 1959 when the society was renamed the British Geriatrics Society to emphasise the scientific basis of elderly medicine.

This meeting was to begin a revolution in the delivery of elderly care services. These pioneers persuaded the Minister of Health to appoint more geriatricians as part of the hospital consultant expansion of the new NHS. Following Marjory Warren's example, frail or disabled patients were to be under the care of a geriatrician and comprehensively assessed by an interdisciplinary team. Those who recovered were discharged home; those who were frail but did not require 24 hour nursing care went to long stay annexes. Patients previously thought to be "senile" or disabled were reassessed, and often found to have modifiable organic disease; many could be rehabilitated. As more older patients returned home, there was more space on the wards, which were repainted and upgraded.

\section{Development of orthogeriatrics}

Two orthopaedic surgeons merit particular attention: Cosin and Devas, and one physician, Bobby Irvine.

Lionel Cosin was the originator of the geriatric day hospital, ${ }^{31}$ and also a pioneer of orthogeriatrics and rehabilita- tion. He trained as a general surgeon, but had a genius for rehabilitation. Initially he worked at Orsett in Essex in 1940, where he operated on war casualties. He also took over responsibility for 300 chronic sick beds. Cosin started admitting patients who were thought to require permanent care as a result of femoral neck fracture. Having operated on them, he started early rehabilitation with the help of a physiotherapist, and many were discharged. Cosin moved to Oxford where he developed the first purpose-built geriatric day hospital (essentially a hospital without beds) which opened in $1957 .{ }^{32}$ Cosin recognised the need to get older people back to their own homes. In the day hospital they could continue to have multidisciplinary assessment, medical treatment, and rehabilitation. The objectives of geriatric day hospitals were later defined by Brocklehurst and Tucker. ${ }^{33}{ }^{34}$ These included medical and nursing care, rehabilitation, social and recreational activities, and relief of caregivers.

Michael Devas was appointed orthopaedics consultant in Hastings in 1957. He regarded himself as a "humble carpenter" and needed "physicians to tell him what was wrong with the patients". ${ }^{35}$ He collaborated with his colleague Bobby Irvine, a consultant geriatrician, on combined physician-surgeon ward rounds. In so doing, they created world renowned orthogeriatric liaison in Hastings. ${ }^{36}{ }^{37}$ Devas recommended early operation for even the frailest elderly patients, and encouraged early rehabilitation..$^{38}$ This approach ensured that many of these patients would eventually walk and return home to independence. He stated that "the first step in rehabilitation is the first step"..$^{35}$ Another of his clinical interests was the rehabilitation of elderly amputees. ${ }^{39}$ By emphasising the significance of orthogeriatric rehabilitation, the NSF for older people incorporates this important topic into the falls section (standard 6). ${ }^{40}$

\section{Development of old age psychiatry}

Old age psychiatry began in the early 1950s. Psychogeriatric assessment wards were initially in asylums. Later, ancillary services were introduced, including day hospitals, nursing and residential homes. ${ }^{41}$ To differentiate physical from mental illness in frail older people can be a considerable challenge, testing the combined skills of both physician and psychiatrist Tom Arie pioneered a department where geriatricians and psychiatrists worked hand in glove to deliver effective medical care. ${ }^{42} \mathrm{He}$ developed the psychiatric-geriatric assessment unit, which at the time had political support. ${ }^{434}$ It later became clear that such units were not essential, provided that both services were in close proximity to facilitate liaison between the specialties. This approach remains in place today.

Day care has been used for many years by psychiatrists. It has been described as a "gift at the end of the war in 1946 to medicine". Arie succinctly defines the role of day care as extending the reach of psychiatry services to people for whom institutional care is either unnecessary or undesirable or unavailable. ${ }^{45}$

\section{Geriatric medicine "heroes"}

Many doctors have made important contributions to the care of older people. Space does not allow us to celebrate all of them, but we have picked out some of the people who have helped improve the care of old people and heightened the status of the specialty (box 3).

\section{Geriatric medicine innovations}

The innovations in elderly medicine pioneered or adapted by geriatricians can be divided into themes and services.

\section{Themes}

- Awareness of atypical and non-specific presentation of acute illness in old age.

- A whole person approach to older people with co-morbidity and complex disability. 


\section{Box 3: "Heroes" of the specialty}

\section{- John Agate (1919-98)}

Former consultant geriatrician in Bradford, he looked after 730 patients single handed and developed a psychogeriatric assessment unit. He moved to lpswich and pioneered geriatrics in East Anglia, converting long stay services to acute medicine for older people with effective rehabilitation. ${ }^{46}{ }^{47}$

\section{- William Ferguson Anderson (1914-2001)}

The first professor of elderly medicine, he was appointed in Glasgow in 1965. A pioneer of geriatric outreach clinics, he established a famous partnership with the general practitioners of Rutherglen Health Centre. ${ }^{48}$

\section{- John Brocklehurst (1924-)}

Former Professor of Elderly Medicine, Manchester. An academic with a particular interest in the problems of incontinence. He has published very extensively and is the author of one of the leading textbooks of elderly medicine. ${ }^{49}$

\section{- Hugo Droller (1909-95)}

The first consultant geriatrician appointed in Leeds in 1950, he was initially responsible for 1300 patients. His approach to rehabilitation using a gymnasium was unique. He introduced occupational therapy and instituted outpatients clinics. Another innovation was a relatives' clinic. ${ }^{50}$

\section{- Bernard Isaacs (1924-95)}

Former Professor of Elderly Medicine, Birmingham. He was particularly interested in the rehabilitation of stroke patients and pioneered stroke unit development. $\mathrm{He}$ described the "giants" of geriatrics: instability, immobility, intellectual impairment, and incontinence. ${ }^{51-53}$

\section{-Eluned (Lyn) Woodford-Williams (1913-84)}

Consultant geriatrician who with her senior colleague Oscar Olbrich established geriatric services in Sunderland in the 1950s, with an emphasis on the need for acute intervention. Pioneered age based care admitting all patients over 65 years irrespective of needs for comprehensive geriatric assessment. ${ }^{54}$

- Interdisciplinary team working and comprehensive geriatric assessment.

- The central importance of rehabilitation.

- Recognition of caregivers' stress; respite care.

- The teaching of geriatric medicine to medical undergraduates.

\section{Services}

- Multidisciplinary case conference.

- Geriatric day hospital.

- Domiciliary visits (visits by a geriatrician to a patient at home at the request of the general practitioner)

- Community geriatrics.

- Outreach clinics in general practitioner surgeries.

- Old age psychiatry.

- Orthogeriatric liaison.

- Stroke rehabilitation units and services.

- Specialty clinics-for example, falls, parkinsonism, stroke.

- Rapid assessment clinics.
Box 4: Recommendations, Royal College of Physicians of London, $1977^{57}$

- General medical and geriatric facilities to be integrated.

- Physicians in training appointed as general physicians with an interest in elderly medicine.

- Multidisciplinary approach to elderly care.

- Undergraduate and postgraduate training in elderly care of every doctor.

- Elderly medicine to become component of MRCP syllabus.

- Increased involvement of general practitioners in the medicine of old age.

- Local authority residential care review.

- Review of elderly mental health services.

\section{The 1960s and 1970s: expansion and antipathy}

Remarkable improvements occurred in the medical care of patients who were managed on geriatric units. There was a rapid increase in the number of consultant geriatrician appointments in the 1960s. From a total of four geriatricians in 1947, there were over 300 by 1973, many from overseas. Academic departments became established. The first chair of geriatric medicine was established in 1965 in Glasgow. ${ }^{48}$

Despite the increase in numbers of geriatricians, there were still staffing problems. Some general physicians questioned the need for a separate specialty; it was sometimes considered a specialty to turn to for those doctors who could not make the grade elsewhere. Some believed that geriatrics was a third rate specialty, with an inferior status (echoing the image of a "workhouse doctor" $\left.{ }^{\prime \prime 5}\right)$. This antipathy to geriatrics was reflected in negative attitudes on the part of many trainees, who regarded a post in geriatrics with disdain. Medical students were not inspired by the image of geriatrics. One student however questioned this, and asked why so many students and doctors failed to see the exciting potential of the specialty. $^{56}$

\section{INTEGRATION OF GERIATRICS WITH GENERAL MEDICINE}

In 1977 a Royal College of Physicians of London working party addressed the many concerns about the future of geriatric medicine. ${ }^{57}$ It acknowledged problems of recruitment, future development, long stay care, and acute hospital medicine. Geriatricians had been increasingly sharing the work of general physicians in the 1970s, participating in acute unselected general medicine take, and continuing care of young general medical inpatients.

The call for integration with general medicine came when services for elderly people had evolved into one of three models:

(1) Traditional or needs based, where geriatricians take selected referrals from other consultants, with a view to rehabilitation, or, if appropriate, placement in long term care.

(2) Age defined care (irrespective of patients' needs) based on an arbitrary age cut off (usually 75 years and over).

(3) Geriatric services fully integrated with general medicine.

Integration was first introduced in Newcastle upon Tyne in 1973. Evans described a system of three reception units accepting all patients irrespective of age. ${ }^{58}$ Each unit was staffed by a consultant physician, one of which had a specialist interest in elderly medicine. All patients had full access to diagnostic facilities for their acute care, and if required could be referred to the geriatrician who had access to all rehabilitation services (box 5).

Bagnall et al described their experience of one of the first successful age defined comprehensive models of care. ${ }^{59}$ This model was introduced in Hull in 1970 (box 6). A single ward 


\section{Box 5: The benefits of Evans' model}

- Transfers for rehabilitation kept to a minimum (inappropriate transfers avoided)

- All junior medical and nursing staff gain experience in looking after older people.

- Rotations between geriatrics and the other medical specialties.

- Good coordination of acute and rehabilitation services.

- Better access to diagnostic and therapeutic facilities for older patients.

- Single admission point for general practitioners.

- More efficient bed usage.

- Avoidance of professional isolation of consultant geriatrician.

\section{Box 6: The Hull model of age defined care}

- Mean length of stay reduced from 186 to $<30$ days.

- Discharges increased from 1532 to 4294 patients lover seven years).

- $20 \%$ reduction in patients requiring long term care.

- $8 \%$ of admission requests dealt with by outpatient clinic, social services, or day hospital treatment.

- The need for dedicated long stay wards eliminated (these patients stayed in the ward of admission).

- Staff morale considerably improved.

dealt with all admissions over 75 . This approach was successful in providing a highly efficient hospital service to many older people.

Protagonists of the age defined model argued that it was convenient and suited general practitioners and admitting junior doctors for placement of ill elderly patients in hospital with dedicated teams. The principal disadvantage is the exclusion of younger patients with complex disabilities. Proponents of the integrationist model argued that their patients had better access to specialist physician opinion and investigation. An argument against this model is the potential for geriatricians to become less interested in rehabilitation of disabled old people, and to concentrate on the demands of the acute general medical take. The debate for and against integration has continued and remains largely unresolved.

\section{SOME CONTEMPORARY THEMES}

\section{Community geriatrics}

There are now calls for geriatricians to do more work outside hospital ( 50 years after Sheldon championed community geriatrics). Proponents of the "community geriatrician" suggest that this is the best way to coordinate prolonged effective rehabilitation of older people, rather than the shorter more intensive care in district general hospitals, with suboptimal aftercare.$^{60}$ Community geriatricians could ensure that assessment of older people outside hospital is truly comprehensive, being based on accurate diagnosis. They might be able to prevent some hospital admissions (though this has yet to be proved). Most UK trainees in geriatrics currently have little formal training in community geriatrics. (A recent survey of 268 specialist registrars in the UK showed less than half had visited a community hospital. ${ }^{61}$ ) For those trainees who wish to take up a community consultant post, changes will have to be made to the elderly medicine training curriculum to incorporate community training. Community geriatrics may de-skill geriatricians in acute care if too much time is spent outside hospital. General practitioners who would otherwise have been looking after these patients may feel it inappropriate for geriatricians to take up practice in primary care (though some would doubtless welcome a geriatrician's expertise, especially in nursing homes).
National Service Framework for older people

NSFs set national standards and define service models for particular patient groups. The NSF for older people has several objectives which include removal of age based rationing of health care, provision of person centred care, the promotion of independence of older people, and arranging services to suit individual patient needs. ${ }^{40}$ The NSF also addresses other specific areas of elderly medicine such as falls, stroke medicine, and mental health. It is a response to the increasing number of older people requiring health care and with a decline in the number of acute medical beds for older people (about 25 000) since 1990. By 2031, there will be 18.6 million people over 60 years, and the number of those over 90 years old requiring health care will have doubled ${ }^{62}{ }^{63}$ With the problems of age based rationing being increasingly reported, ${ }^{64}$ action is needed to counter this injustice. The NSF details a 10 year plan to deal with these issues and champion the welfare of older people.

Though the intentions of the NSF are admirable, it has weaknesses. The most controversial issue is standard 3-intermediate care, which advocates the provision of integrated services, avoidance of " unnecessary" admission to long term or acute hospital care, and maximising independent living. Five thousand intermediate care beds are to be created. This approach (for which the evidence base is lacking) will require investment and could be at the expense of existing specialist rehabilitation units. ${ }^{65}$ Closing down these beds might be a retrograde step. As Evans and Tallis point out, the word inappropriate (referring to hospital admission and bed occupancy of older people) is contentious and too readily attached to patients. ${ }^{65}$ Many elderly patients who do not get admitted to hospital might benefit from admission and comprehensive geriatric assessment. If ill or disabled older people are diverted from hospital, they might not receive optimum investigation and treatment. An initiative that purports to remove ageism may itself foster ageist clinical practice.

\section{Academic geriatrics}

Every medical school now has a department of geriatric medicine. Many produce high quality research but as a specialty, geriatrics has not been as successful in groundbreaking research as other medical specialties. Part of this is because the nature of the subject and analysis of patients with complex conditions is more difficult than focused work on a single problem. The reductionist approach to research is not always appropriate here. A challenge is to research those important aspects of elderly care which are common but relatively neglected. The strengthening of geriatric research is now a prime objective of academic geriatricians.

\section{CONCLUSION}

Geriatrics has a come a long way since the days of workhouse medicine. Services for elderly people have improved beyond recognition in the decades since the British Geriatrics Society began. There is still much to be done, but there has possibly never been a better time to be old and ill or disabled in the UK. Geriatric medicine has built on the principles and practice of Marjory Warren and other pioneers. The negative views of the specialty have been replaced by optimism. The specialty's many strengths include multidisciplinary team working, comprehensive geriatric assessment, improved hospital environments for many older people, earlier intervention to investigate, treat and, wherever possible, to rehabilitate older people and discharge them to their own homes.

\section{MULTIPLE CHOICE QUESTIONS (ANSWERS AT END OF REFERENCES; TRUE (T)/FALSE (F))}

Q1. The term geriatrics originates from two Greek words: iatros, a surgeon and geros, an old man. 


\section{Box 7: Key references}

- Nascher IL. Geriatrics. New York Journal of Medicine 1909;90:358-9.

- George J, Young JB. Joseph Sheldon and the social medicine of old age: 40 years on. Care of the Elderly $1989 ; 1: 272-4$.

- Warren MW. Care of chronic sick. A case for treating chronic sick in blocks in a general hospital. BM 1943;ii:822-3.

- Evans JG. Integration of geriatric with general medical services in Newcastle. Lancet 1983;i: 1430-3.

- Evans JG, Tallis R. A new beginning for elderly people? BM 2001;302:807-8.

Q2. Voluntary hospitals (today's teaching hospitals) avoided admitting elderly patients for fear of "bedblocking".

Q3. Home assessment visits are requested by general practitioners and are remunerated.

Q4. The modern Ripple Mattress was pioneered by a geriatrician, Norman Exton-Smith.

Q5. The practice of intermediate care which is incorporated into the National Service Framework for older people is evidence based.

\section{ACKNOWLEDGEMENTS}

We are very grateful for the information and advice of Professor George Adams, Dr Michael Denham, and the late Dr Bobby Irvine. Their constructive criticisms and insights helped us enormously in preparing this article.

\section{Authors' affiliations}

A Barton, G Mulley, Department of Elderly Medicine, St James's University Hospital, Leeds

\section{REFERENCES}

Bennett G, Ebrahim S. The essentials of health care of the elderly. London: Edward Arnold, 1992.

2 Wakley T. Mortality in poor-law workhouses. Lancet 1840-1;ii:194.

3 Richardson R, Hunvitz B. Joseph Rogers and the reform of workhouse medicine. BM 1989;299:1507-10.

4 Scott CJ. George Day and diseases of advanced life. The Practitioner 1975;214:832-6

5 Day GE. A practical treatise on the domestic management and most important diseases of advanced life. London: T and W Boone, 1849.

6 Isaacs B. An introduction to geriatrics. London: Balliere, Tindall and Cassell, 1965

7 Charcot JM. Clinical lectures on senile and chronic diseases. London: New Sydenham Society, 1881.

8 Pathy MSJ. Principles and practice of geriatric medicine. 3rd Ed. Chichester: John Wiley, 1998

9 Nascher IL. Geriatrics. New York Journal of Medicine 1909;90:358-9.

10 Matthews DA. Dr Marjory Warren and the origin of British geriatrics. J Am Geriatr Soc 1984:32:253-8.

11 Warren MW. Care of chronic sick. A case for treating chronic sick in blocks in a general hospital. BM 1943;ii:822-3.

12 Warren MW. Care of the chronic aged sick. Lancet 1946;i:841-3.

13 George J, Young JB. Joseph Sheldon and the social medicine of old age: 40 years on. Care of the Elderly 1989;1:272-4.

14 Sheldon JH. The social medicine of old age. Oxford: Oxford University Press, 1948 .

15 Irvine RE. Norman Exton-Smith. Munk's Roll 1989-93;9:160-6.

16 Amulree L, Sturdee EL. Care of the chronic sick and the aged. BM 1946;i:617-18.

17 Amulree L. Twenty five years of geriatrics. Br J Clin Pract 1971;25:97-104.

18 Exton-Smith AN, Crockett GS. The chronic sick under new management. Lancet 1949;i:1016-18.

19 Exton-Smith AN. An investigation on the aged sick in their homes. BM 1952; ii: 182-6

20 Exton-Smith AN. Progressive patient care in geriatrics. Lancet 1962;i:260-2.
21 Bliss MR, McLaren R, Exton-Smith AN. Preventing pressure sores in hospital: controlled trial of a large-celled ripple mattress. BM 1967;i:394-7.

22 Exton-Smith AN. Medicine in old age. Accidental hypothermia. BM 1973;iv:727-9

23 Collins KJ, Exton-Smith AN, James $M H$, et al. Functional changes in autonomic nervous responses with ageing. Age Ageing 1980;9:17-24.

24 Exton-Smith AN. Problems of diet in old age. J R Coll Physicians Lond 1975:9:148-60.

25 Faccinin JM, Exton-Smith AN, Boyde A. Disorders of bone and fracture of the femoral neck. Evaluation of computer image analysis in diagnosis. Lancet 1976;i: 1089-92

26 Van der Cammen TJ, Simpson JM, Fraser RM, et al. The memory clinic. Br J Pschyciatry 1987; 150:359-64.

27 Irvine RE. George F Adams - "Our founders" series. BGS Newsletter 1989

28 Adams GF. Eld health-origins and destiny of British geriatrics. Age Ageing 1975;4:65-8

29 Irvine RE. Forty years on. BGS Annual Report 1986-87.

30 Howell TH. Origins of the BGS. Age Ageing 1974;3:69-72.

31 Irvine RE. Lionel Cosin-“Our founders" series. BGS Newsletter 1989.

32 Cosin L. The place of the day hospital in the geriatric unit. The Practitioner 1954:172:552-9.

33 Brocklehurst JC, Tucker JS. Progress in geriatric day care. London: King's Fund for London, 1970.

34 Zeeli $\mathbf{D}$, Isaacs $B$. The efficiency and effectiveness of geriatric day hospitals. Postgrad Med J 1988;64:683-6.

35 Irvine RE. Michael Bertrand Devas. BM 1999;318:946.

36 Irvine RE. Michael Bertrand Devas. BGS Newsletter 1999.

37 Irvine RE. Geriatric orthopaedics in Hastings: the collaborative management of elderly women with fractured neck of femur. Advanced Geriatric Medicine 1983: 130-6.

38 Devas MB. Geriatric orthopaedics. BM 1974;i: 190-2.

39 Devas MB. Early walking of geriatric amputees. BM 1971;i:394-6.

40 Department of Health. NSF for older people. London: Department of Health, March 2001.

41 Omu N, Butt A, Shabbir S. Old age psychiatry. BM 2002;324:153.

42 Arie T, Dunn T. A "do-it-yourself " psychiatric-geriatrics joint patient unit. Lancet 1973;ii:1313-16.

43 Department of Health and Social Security. NHS psycho-geriatric assessment units. London: DHSS, circular HM (70) 11.1970.

44 Department of Health and Social Security. Services for mental illness related to old age. London: DHSS, circular HM (72) 71.1972.

45 Arie T. Day care in geriatric psychiatry, 1978. Age Ageing 1979;8(suppl):87-91.

46 Moore-Smith B. John Norman Agate. BMU 1999;318:401

47 Irvine RE. John Agate-" Our founders" series. BGS Newsletter 1989

48 Wykes L. Sir William Ferguson Anderson. BGS Newsletter 2001.

49 Brocklehurst JC, Fillit HM, Tallis JC. Brocklehurst's textbook of geriatrics and gerontology. 5th Ed. London: Churchill Livingstone, 1998.

50 Droller H. Falls among elderly people living at home. Geriatrics $1955 ; 10: 239-44$

51 Isaacs B, Marks R. Determination of outcome of stroke rehabilitation. Age Ageing 1973;2:139-49.

52 Isaacs B. Five years experience of a stroke unit. Health Bull (Edinb) 1977:35:94-8.

53 Isaacs B. Ageing and the doctor. In: Hobman D, ed. The impact of ageing. London: Croom Helm, 1981

54 Irvine RE. Eluned Woodford-Williams. Munk's Roll 1984-88;8:550.

55 Report of the Working Party of the Royal College of Physicians. Medical care of the elderly. Lancet 1977;i: 1092-5.

56 Cross VH. Geriatric medicine-death and rebirth. BM 1977;ii:816-17

57 Royal College of Physicians. Working party on medical care of the elderly. London: RCP, 1977.

58 Evans JG. Integration of geriatric with general medical services in Newcastle. Lancet 1983;i:1430-3.

59 Bagnall WE, Datta SR, Knox J, et al. Geriatric medicine in Hull: a comprehensive service. BMU 1977;ii:102-4.

60 Young JB, Philp I. Future directions for geriatric medicine. BM 2000;320:133-4

61 Bansal A, Young J. A survey of community training and experience for specialist registrars in elderly-care medicine. Age Ageing 2001;30:533

62 Khaw KT. How many, how old, how soon? BN 1999;319:1350-2.

63 Tonks A. Medicine must change to serve an ageing society. BM 1999:319:1450-1.

64 Dudley NJ, Burns E. The influence of age on policies for admission and thrombolysis in coronary care units in the United Kingdom. Age Ageing 1992;21:95-8.

65 Evans JG, Tallis R. A new beginning for elderly people? BM 2001;322:807-8.

\section{ANSWERS}

Q1. F, iatros means healer; Q2. T; Q3. F, home visits are instigated by geriatricians for patient assessment preadmission and unlike domiciliary visits are not remunerated; 4 . T; 5 . F. 